\title{
Learning from Japan for Possible Improvement in Existing Disaster Risk Management System of Nepal
}

\author{
Ganesh Kumar Jimee ${ }^{1,2^{*}}$, Kimiro Meguro3 ${ }^{3}$, Amod Mani Dixit ${ }^{2,4}$ \\ ${ }^{1}$ Institute of Industrial Science, The University of Tokyo, Tokyo, Japan \\ ${ }^{2}$ National Society for Earthquake Technology-Nepal (NSET), Lalitpur, Nepal \\ ${ }^{3}$ International Center for Urban Safety Engineering, Institute of Industrial Science, The University of Tokyo, Tokyo, Japan \\ ${ }^{4}$ Asian Disaster Risk Reduction Network (ADRRN), Kathmandu, Nepal \\ Email: ^gjimee@nset.org.np, ganesh710@gmail.com
}

How to cite this paper: Jimee, G.K., Meguro, K. and Dixit, A.M. (2019) Learning from Japan for Possible Improvement in Existing Disaster Risk Management System of Nepal. Open Journal of Earthquake Research, 8, 85-100.

https://doi.org/10.4236/ojer.2019.82006

Received: November 17, 2018

Accepted: May 24, 2019

Published: May 27, 2019

Copyright $\odot 2019$ by author(s) and Scientific Research Publishing Inc. This work is licensed under the Creative Commons Attribution International License (CC BY 4.0).

http://creativecommons.org/licenses/by/4.0/

\begin{abstract}
Nepal and Japan, both are multi-hazard prone countries having experience of devastating disasters. It is difficult, if not impossible, to stop natural hazard events at source. However, the impact can be reduced significantly by preventing them from turning into disasters. The impact of disasters can vary depending on the capacity to handle the situation; and the capacity depends on the level of preparedness and mitigation measures taken in advance. Japan has set example for the rest of the world when it comes to Disaster Risk Management (DRM). Recovery and reconstruction after disasters are not just to develop the area as it was earlier, but it has to be taken as an opportunity for developing better than earlier, which is called as "Build Back Better". This concept was raised by Japanese Government in UN World conference, Sendai in 2015 [1]. Dynamic, evolutionary and proactive DRM policy and plans with innovation, and the use of science and technology to find solutions, and effective implementation of the policy and plans, coupled with the culture of safety among the citizens, and the spirit of never give up "Nana KarobiYa Oki" (Seven times fall down, Eight times get up), are the unique features that every country should learn from Japan's DRM mechanism. This paper is an effort to buy-in the good practices from Japan to improve DRM system in Nepal. It is a product of three-month intensive research in the University of Tokyo under a $\mathrm{PhD}$ research that consisted of reviewing existing DRM documents and several interactive meetings with stakeholders in Japan.
\end{abstract}

\section{Keywords}

Learnings from Japan, Disaster Risk Management Act, Disaster 
Countermeasures, Earthquakes, Nepal

\section{Background}

Hundreds of thousands of lives are being lost globally due to natural hazard events and a huge loss amounting US $\$ 1.5$ trillion has been lost during the last decade alone, and this trend is continuing as exposure in hazard-prone countries grow more rapidly than vulnerability which is reduced [2]. Asia is considered the most vulnerable continent with 83 percent population affected by disasters globally during 1991-2000. Further, in 2015, almost 32,550 people were killed, more than 108 million people were affected and assets US $\$ 70.3$ billion were damaged by 574 disasters. Out of the disaster-related deaths globally, 67 percent were in Asia [3].

Japan, though it is small country covering just 0.25 percent area of the earth, due to its geographical, topographical and metrological features, it is highly prone to different types of natural hazards mainly torrential rains, typhoons, heavy snowfalls, earthquakes and tsunamis, etc. It is considered more prone to earthquake because of its location at the crushing point of four tectonic plates; about $20 \%$ of the world's earthquakes of magnitude 6 or greater have occurred in or around Japan [4]. It is also said that now the country has entered into a seismically active period and experts have estimated that within next 30 - 50 years; there is a possibility of occurring 4 - 5 earthquakes of M8 and 40 - 50 earthquakes of M7 [5]. The country has already gone through many earthquakes, significantly large human and property losses such as the Great East Japan Earthquake in 2011 and the Kobe Earthquake in 1995. Beside earthquakes, the country is also known as the home of around 110 active volcanoes as it sits in the Circum-Pacific Volcanic Belt or "Ring of Fire" [6] and also suffers from many different kinds of other natural disasters.

The Prime Minister of Japan H.E. Shinzo Abe said while addressing the 3rd UN World Conference on Disaster Risk Reduction in 2015 in Sendai, "Japan is a disaster-prone country and has been working hard on disaster risk reduction for a long time" [2]. Japan has experienced many natural disasters, realizing this fact the Government of Japan has paid much attention for disaster risk reduction and emergency management through encouraging the mechanism of self-help, mutual assistance and public support. The Government has continually been undertaking initiatives that constitute "public support", which include measures undertaken before disaster strikes: for example, building embankments and other hard infrastructure measures, as well as soft infrastructure measures, such as conducting drills [7]. It has been considered as one of the best examples in the world for disaster risk management.

Nepal, located on the astride boundary of two active tectonic plates has diverse physiography and climatic variation, is prone to multi-hazard events [8]. Nepal recurrently is exposed to landslides, fires, earthquakes, floods, glacier lake 
outburst floods (GLOF), thunderstorms and avalanches, etc. causing significant loss of property and lives every year, in average 2 deaths every day [9] [10]. Lack of awareness among the people at different levels, lack of timely revision and effective implementation of policy and guidelines, haphazard urbanization and development activities, etc. are the major causes to turn the hazards into devastating disasters [11] [12]. Nepal has recently enacted Disaster Rick Reduction and Management Act (DRR\&MA, 2017), which has adopted recent global trend of focusing proactive approach in DRM, and several policies in support of DRR\&MA, have been developed. Hence, in guidance of such act and policies, Nepal has to develop long term strategic plans for effective disaster management. In this context, the practices adopted in the countries like Japan, which has already set examples in effective DRM, can be taken as guidance for effective DRM in Nepal.

\section{Disaster Risk Management (DRM) Policy Environment in Japan}

Globally in recent decades, there have been several initiatives in disaster risk management. National authorities, regional and international stakeholders have made investments in terms of time, expertise and budget to better understand disaster genesis and dynamics. As a result of several global conferences and discussions, and analyses of lessons learned from different disasters, now the focus has largely been shifting from relief and rehabilitation to disaster risk reduction and management [3]. In the context of Japan, the Government has considered as the national priorities to protect the country's land, saving lives of its people, livelihood and property from disasters [4]. Further it has made a significant investment for reducing risk rather than spending more in emergency response activities after disasters, good example of investing 51 percent in "mitigation and preparedness" of the total disaster-related project budgets was done during 1990-2010 [1].

Japan has three levels of government namely, national government, prefectures, and municipalities. In each level the respective heads have full responsibility in their jurisdiction. Accordingly, comprehensive disaster prevention plans have been developed defining the roles and responsibilities to be performed in different stages. The national council on disaster management, led by the Prime Minister, has been established under the Basic Act on Disaster Management, which also assigns responsibilities to the ministers, heads of public institutions and experts. The main role of the council is to formulate and promote major disaster management policies, including the Basic Plan of Disaster Management.

Though Japan has a quite long history of disaster management policy development, the Disaster Countermeasures Basic Act was a turning point for strengthening disaster management system when it came into effect in 1961 after the 1959 Ise-wan Typhoon killing 5098 people. This act clearly defines the roles and responsibilities for federal government and develops acumulative and organized disaster prevention structures [4]. It is important to note that Japan has a good practice of evaluating response situations during each disaster and the lessons 
learned from those disasters are analyzed to reflect in current organizational mechanism at different levels to develop required tools and materials, and accordingly amendments/revisions are made in existing policies and guidelines [13]. Hence, the act and policies are revised as per the context based on the current need and situation. For instance, since its first enactment in 1961, the Basic Act on Disaster Management has been amended six times as of 2016 [7]. Realizing that some 80 percent of total deaths in the 1995 Kobe Earthquake were due to the collapsed of buildings, having low safety against earthquake because they were constructed prior to the 1981 building code came into action [6], the Act on Promotion of the Earthquake-proof Retrofit of Buildings was enacted [7]. The Tohoku Earthquake and Tsunami (also known as the Great East Japan Earthquake and Tsunami) has given a lesson that the need of Extreme Disaster Management Headquarters to grasp a whole picture of the damage and action to be taken immediately without waiting requests for assistance from the affected areas in big disasters [14]. Several policies and acts were developed and amended after the Tohoku Earthquake, such as the Act on Promotion of Tsunami Countermeasures 2011; Act on Development of Areas Resilient to Tsunami Disasters 2011; Amendment of Disaster Countermeasures Basic Act; Act for Establishment of the Nuclear Regulation Authority, 2012; Act on Reconstruction from Large-Scale Disasters; Amendment of the Act on Promotion of the Earthquake-proof Retrofit of Buildings, etc. [4]. Similarly, after the 2016 Kumamoto Earthquake, revisions were made mainly on the Basic Plan for Disaster Risk Reduction; the Guide to Preparing Detailed and Practical Evacuation Plans in Case of Volcanic Eruption and the Guidelines for Evacuation recommendations [7].

\section{Disaster Management Planning}

Acts and legal provisions in Japan are implemented, and continuously revised based on the experiences and lessons from each and every disaster. The result is gradual and sustained enhancement of resilience on a long-term period. As stipulated in the Basic Act on Disaster Management, there are four levels of basic plans for Disaster Management in Japan, namely, National Basic Plan for Disaster Risk Reduction, Prefecture Basic Plan for Disaster Risk Reduction, Municipality Basic Plan for Disaster Risk Reduction and Community Disaster Risk Reduction Plan (Figure 1). The National Basic Plan was developed in 1963 and revised several times including the latest revision in 2017, mainly based on the learnings from the disasters and changes in policies and government's structure. This plan was entirely revised in 1995 after the experiences from the 1995 Earthquake Disaster. This plan is considered the foundation for the country's disaster management measures [15]. The National Basic Disaster Risk Reduction Plan has to be approved by the National Council on Disaster Management. Established in the Cabinet Office based on the Disaster Countermeasures Basic Act, it is chaired by the Prime Minister and comprises all members of the Cabinet, heads of major public corporations and experts. It deals with policies-related issues involving all the ministries of the Cabinet. All 47 prefectures have the 


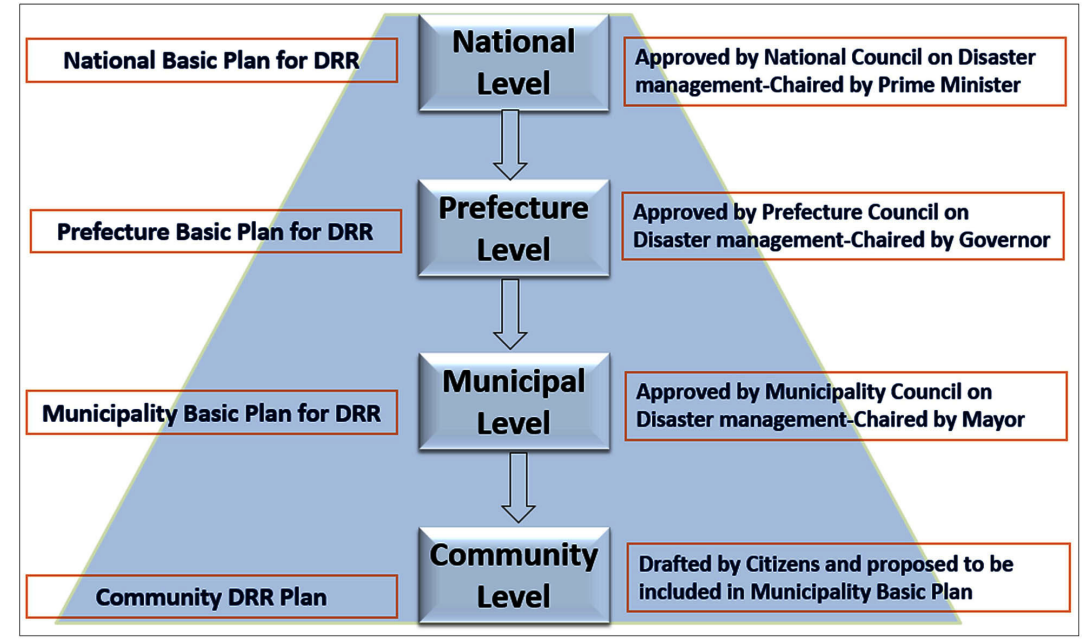

Figure 1. Basic plans for disaster management in Japan. Source: Cabinet office Japan (modified).

Prefecture Basic Plan for Disaster Risk Reduction approved by the Prefecture Council on Disaster Management, chaired by the governor. Similarly, all municipalities have the Municipality Basic Plan for Disaster Risk Reduction approved by the Municipality Council on Disaster Management chaired by respective mayors. The Community Disaster Risk Reduction plan has been newly introduced in the system, which has been drafted by the citizens and is included in the Municipality Basic Plan [16].

All public and legal bodies, including banks, companies, lifeline utilities, are obliged to participate in Central Disaster Management Council and prepare the Disaster Risk Reduction Operation Plans as per the guidelines of the Basic Plan for Disaster Risk Reduction. Similarly, the Disaster Countermeasures Basic Act obliges the private sectors and the persons taking responsibilities with disaster risk reduction to fulfill their responsibilities. The act also promotes the participation of stakeholders in disaster risk reduction efforts and activities, including encouraging them to take their own preparedness initiatives to cope with disasters and mitigate the adverse effects [15].

\section{DRM Capacity Development and Awareness Activities}

The Government has strategically started different programs to promote understanding and enhance capacity among the DRM stakeholders at different levels. In this connection, the Cabinet Office has initiated a "Program for Developing Disaster Management Specialists" for developing people who can promptly and appropriately support disaster management including disaster response and can form a network between national and local authorities. It has been providing trainings on different themes at different locations based on the respective context. The Central Disaster Management Council of the Government sets out basic guidelines for the drill exercises at national and local levels and outlines the "Disaster Reduction Drill Plan" stipulating overview of drills and exercises im- 
plemented by the government. To enhance disaster resilience of community and to reduce disaster risk involving all stakeholders, the Government has declared 1st of September as "Disaster Prevention Day". Every year, nation-wide, the whole week of September 1 is observed as "Disaster Prevention Week" conducting different disaster risk reduction and awareness activities.

Similarly, November 5 has been designated as "Tsunami Disaster Prevention Day" and observed nation-wide conducting tsunami awareness and risk reduction activities. Based on the learnings from past disasters, schools and communities are provided with awareness, education and skill development trainings through different means, such as publications, publication materials, online and hands-on trainings, etc. Considering the spirit of self-help and mutual assistance, and to strengthen the capacity of the communities, communities are encouraged to develop Community Disaster Management Plans including disaster preparedness, risk reduction, capacity enhancement activities. Realizing the important role of volunteers during disasters, as large number of volunteers assisted in earthquake disaster in 1995, the Government has declared 17 January as the "Disaster Reduction and Volunteer Day", and the whole week of 15 to 21 January as "Disaster Reduction Volunteer Week". The events organized throughout the country in coordination and cooperation with national and local authorities, local communities and other stakeholders [15]. However, as shared by one of the active volunteers during interaction for this research, now there are problems of dwindling and ageing membership due to the engagement in other activities of the young generations such as in full time jobs and education, etc. The Government assists circulating "Business Continuity Guidelines" to the private enterprises and companies for developing Business Continuity Plans (BCPs) to ensure continue operation of business, safety and security of employees, and reducing risk of disasters [4].

\section{Major Disasters in Japan and Countermeasures}

Japan has been experiencing fatalities and loss of property repeatedly due to a variety of hazards from the ages. Beside earthquakes, Japan has a big threat of volcanoes as it sits in "Ring of Fire". Japan shares almost $10 \%$ of the total active volcanoes in the earth [4]. The snow related hazards are also common. For example, during 2010-2012, more than 100 deaths were counted each winter. Similarly, the country is prone to different types of water and wind-related hazards. Among them, floods, landslides, sedimentations, tidal waves and storms, typhoons, torrential rains are common.

Disasters in Japan, for the purpose of disaster management, can be broadly categorized in two types-1) natural hazard disasters and 2) accident disasters [4]. The natural hazard includes-earthquake, storm and flood, volcano and snow related hazards, whereas accident disasters include those related to maritime, aviation, rail road, road, nuclear, hazardous materials, large scale fire and forest fire. Japan has developed a well-structured disaster management system. A 
Minister of State for Disaster Management is appointed to the Cabinet, and the Disaster Management Bureau formulates basic policy on disaster management and also responsible for overall coordination on response to large-scale disasters. However, generally in case of any disasters, the respective authorities will manage the situation, depending on the scale and impact. If the scale of disaster is small that will be addressed by the respective municipality. If it is beyond the capacity of municipality, the prefecture will be requested. The central governmentgets involved as well if the capacity of prefecture is short of the needs. However, if the scale of disaster is large enough, the central government does not wait for the call fromlower authorities. Instead, emergency measures are called into action immediately. For example, during the 2014 Hiroshima landslides, the Onsite Disaster Management Headquarters was set up and headed by a State Minister of Cabinet Office. In case of large-scale disaster, a meeting is organized within 30 minutes, meeting and extreme disaster management headquarters will be established led by the Prime Minister [14].

Having experienced many disasters with great loss in terms of human lives and property, Japan's legislation for disaster management addresses all phases of disasters from damage mitigation, preparedness, early warning damage assessment, response, recovery, to reconstruction, with defined roles and responsibilities of various agencies and departments. All relevant stakeholders, including private sectors, get involved in implementing various countermeasures [4]. The initiatives taken and the commitments made by the Government of Japan mobilizing different local, national and international stakeholders for reducing the disaster loss and damage are highly commendable [17]. Countermeasures initiated for some disasters are discussed in the following sections.

\section{Countermeasures for Earthquake}

Studies have pointed out that Japan can be struck by big earthquakes in near future mainly in the areas such as Nankai Trough, the Japan and Chishima Trenches, and directly below Tokyo and Kinki regions [4]. The major trenches and likely earthquake zones are presented in Figure 2.

Considering this fact, the government has paid attention and designated the potential areas and urged the government authorities and other concerned stakeholders including private sectors for implementing disaster reduction measures in accordance with the laws and regulations. The Government is developing a plan to expedite the countermeasures by administrative entities and private sectors. The threatened areas are being prepared for the expected scenario earthquakes suggested by experts. For instance, as the countermeasures for Tokyo Metropolitan Inland Earthquake, enactment of the Act on Special Measures for Tokyo Metropolitan Inland Earthquake (November 2013), designation of areas in need for urgent measures (2014), and formulation of Business Continuity Plan by Central Government, etc.

There are 4377 seismic observation points set up throughout the country. The Japan Metrological Agency (JMA) has the capability to issue information about 


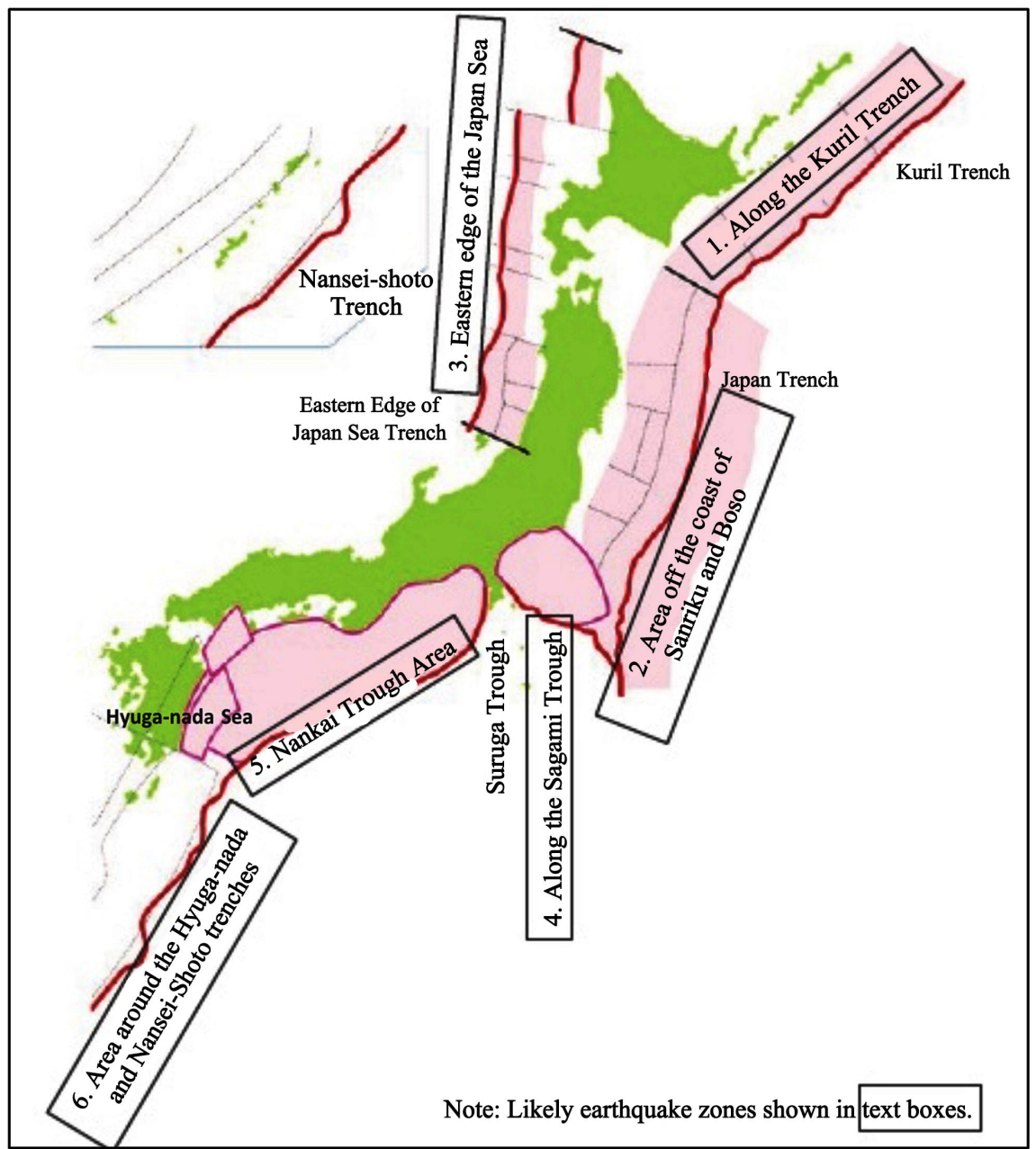

Figure 2. Major trenches and likely earthquake zones. Source: Ministry of Education, Culture, Sports, Science and Technology.

seismic intensity of 3 or greater within about two minutes, and it issues earthquake information report including the epicenter, magnitude and the area experiencing strong shaking. The Policy Framework for Large-scale Earthquake Disaster Prevention and Reduction, the Earthquake Disaster Reduction and Guidelines for Emergency Response Activities, are developed. Similarly addressing all stages of disaster, a guideline for municipalities has been prepared on the countermeasures against earthquakes.

\section{Countermeasures for Volcano}

The Japanese islands are the home to 110 active volcanoes (Figure 3 ). The volcanoes, once they erupt, give very little time for evacuation. Japan has experienced heavy damage by volcanoes in the past. The Government has paid attention for accurate monitoring/observation and timely dissemination of appropriate information for evacuation before and during eruption. JMA has a network of monitoring 47 volcanoes 24 hours a day for issuing eruption warnings [4].

In accordance with the "Guideline for Disaster Management System Concerning Evacuation in the Event of Volcano Eruption (2008)" and the "Recom- 
mendations for Countermeasures against Large-scale Volcano Disaster (2013)", several actions have been taken, such as establishment of Volcano Disaster Management Councils; a wide area coordinating framework consisting of various volcano related government agencies; preparation of volcano hazard maps for different scenarios; development of evacuation plans, routes and methods and establishment of working group for promotion of volcano disaster prevention, etc.

\section{Countermeasures for Tsunami}

Having long and complex coastlines, Japan remains under imminent threat of earthquake induced tsunamis. It has experienced great loss of lives and property in the past $(1896,1933,1944,1946,1960,1968,1970,1983,1993$ and in 2011). The Great East Japan Earthquake and subsequent Tsunami in March 2011 killed more than 18,000 people and caused heavy loss of property in Japan. There have been several efforts made as the countermeasures for tsunami risk reduction. The tsunami warning service was set up in 1952, which consist of 300 sensors [18]. JMA issues the tsunami warnings within 2 to 3 minutes after the earthquake and subsequently gives information about the possible height and arrival time in the respective locations. Network has been developed to transmit such information to the concerned authorities/stakeholders and residents in timely manner. Based on the experiences from the 2011 earthquake and tsunami the Act on Promotion of Tsunami Countermeasures has been developed, which includes strengthening tsunami observation system, education and training and developing required facilities among others.

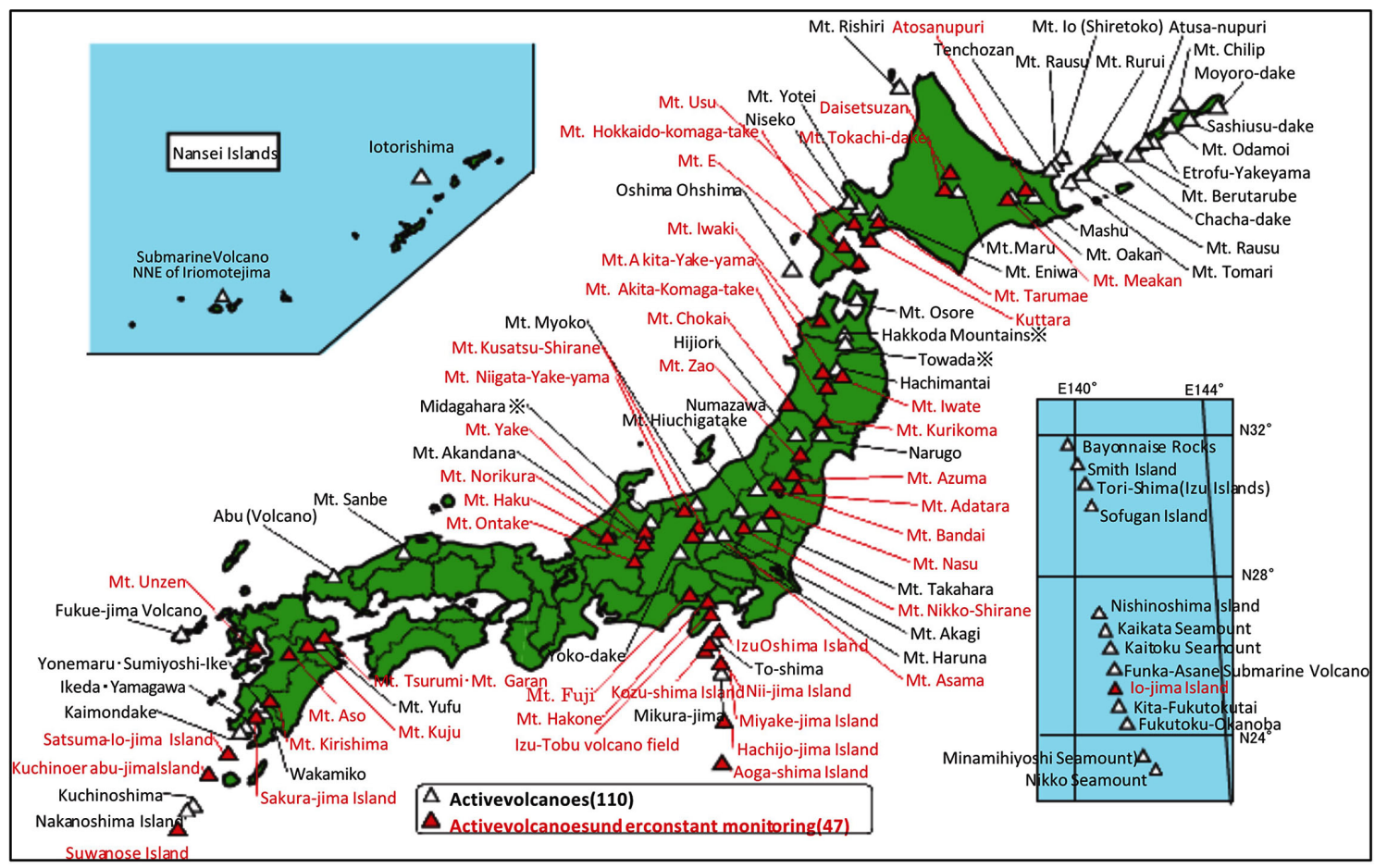

Figure 3. Distribution of active volcanoes in Japan. Source: Cabinet office Japan, White Paper on Disaster Management in Japan, 2015 (Created by the Cabinet Office from the Japan Meteorological Agency Website). 
Similarly, the Act on Development of Area Resilient to Tsunami Disasters provides prescribes for formulating comprehensive plans. The Disaster Countermeasures Basic Act has enabled local authorities to designate the emergency shelter areas.

\section{Countermeasures for Storm and Flood}

It is said that, in Japan, one-half of the population is concentrated in possible inundation areas, which account for about $10 \%$ of the national land [4].

JMA has Automated Meteorological Data Acquisition System for observing meteorological phenomena that cause storm and flood disasters. Based on the automated measures of rainfall, air temperature and wind direction/speed and weather, the JMA announces the forecasts and warnings for preparing against possible disasters. Based on the Flood Control Act and the Sediment Disaster Prevention Act, 417 rivers are covered by flood warning system and 1555 rivers subject to water-level notifications. The municipalities are urged to prepare flood hazard maps and disseminate among the communities. As of March 2014, 1272 municipalities have published such maps. Furthermore, there has been taken several measures such as formulation of Working Group for Studying Comprehensive Counter Measures against Sediment Disasters and Basic Policies for Metropolitan Area Large-scale Water Hazards etc. [4].

\section{Countermeasures for Snow Disasters}

Mainly in winters, the cold winds blowing from Siberia meets with the warm current flowing up the coast from the south bringing heavy snowfalls in Japan. In the winter of 2006, 152 deaths were reported, and more than 100 snow related incidents were reported during 2010-2012 [4].

Incorporating the lessons from heavy snowfall in 2013, the policies and guidelines are being reviewed and revised. Based on Act of Special Measures for Heavy Snowfall Areas, the measures for securing traffic and communication and protecting agricultural land and forestry have been taken. Considering the risk of avalanches, the projects for protecting communities and strengthening the system of warning and evacuation are implemented. The municipalities have taken initiation for preventive measures and conducting public awareness programs in their respective areas.

\section{Unique Features of DRM in Japan}

Having gone through many devastate.ng disasters, including the 1923 Tokyo Earthquake, 1995 Kobe (Great Hanshin-Awaji) Earthquake, 2011 Great East Japan Earthquake and many others, Japan has done more than most setting an example of effective disaster risk management system in the world. Some of the unique features of disaster risk management in Japan, realized in the course of this research are stated here.

\section{Culture of Safety, Part of Life}

Though people don't remember/memorize the plan and policies, most Japanese have good understanding of disaster preparedness measures and hence in- 
ternalized them in their daily life as they have been learning and applying as they have grown up. DRM actions have been taken as a part of everybody's life. The Government has facilitated each sector in such a way that everybody is going in the direction of being and/or developing disaster resilient communities. For instance, special days have been designated by the Government for getting people's attention and encouraging for disaster risk reduction initiatives time and again. The senior Government representatives, including the Prime Minister, get involved in such activities seriously, which has given worth for working jointly among the citizens and taken ownership by all. The Government, local authorities, and even the communities have given high priority for preparedness against disasters. Due to the culture of feeling individuals' responsibility, hard work and sense of humanity for helping each other, no matter how the scale of crisis, Japan has demonstrated recovery in a better way than it was before the disaster. The mechanism of mutual-support is exemplary. As mentioned in the Tokyo Disaster Prevention Plan, about 98 percent of the rescued people were by family and neighbors in the 1995 Kobe Earthquake [19].

"Nana KarobiYa Oki" (Seven Times down, Eight Times Up)

As the famous Japanese proverb, "Nana KarobiYa Oki" (literally it means "Seven times down, Eight times up"). This proverb encourages for never giving up. It has been proven in the context of disaster risk management in Japan. Japan was toppled many times but has never laid down. Instead, it has always bounced back and stood in a better way than it was earlier. The country has taken each disaster as an opportunity for improvement from different aspects. A good example can be taken an efficient response of Japan in the immediate aftermath of so-called triple disaster (earthquake, tsunami and nuclear crises) in 2011 [20]. Regarding the post disaster reconstruction approaches, Japan was the first country bringing the concept of "Build-Back Better" in the UN World Conference, Sendai in 2015 [1].

\section{Science and Technology Based Solutions}

Saving citizens' lives and property is the national priority in Japan. It has made significant investment for disaster prevention and mitigation than focusing only in response activities. Experts and scientists working in different institutions have been involved for disaster risk reduction activities and given responsibility as the members of the Central Disaster Management Council or the member of specialists' groups. The research outcomes have informed for policy formulation, planning and finding practical solutions/countermeasures for DRM at various levels. Japan has developed the world's most sophisticated earthquake early warning system, and the early warning system for many other disasters including, heavy rainfall volcano, tsunami, snow fall, etc., which covers the whole territory of the country. For instance, the Urgent Earthquake Detection and Alarm System (UrEDAS), used by Japan Railway (JR) Group, shuts off the power supply system of running Shinkansen and conventional rail services automatically when preliminary earthquake tremors are detected and deemed likely to interfere with rail services [3]. 


\section{Dynamic, Evolutionary and Proactive DRM Policy Environment}

The Disaster Countermeasures Basic Act, 1961, is the cornerstone of disaster management policy environment in Japan. This sets the foundation for DRM in Japan. Based on this act, several plans and policies have been formulated concerning disaster prevention and mitigation, emergency response, recovery and reconstruction. The Basic Plan for Disaster Risk Reduction, developed under the Disaster Countermeasures Basic Act, sets out the comprehensive and long-term plans for DRM in Japan [3]. Japan has a good practice of evaluating each disaster, and analyzing the gaps, hence based on the analyzed learnings, the existing policies and plans are revised, and if required new plan and policies are developed. For instance, the Disaster Countermeasures Basic Act has been revised several times after its enactment in 1961, and several other policy and plans, such as Basic Disaster Management Plan, have been revised and developed as per the need after different disasters. There are policy and guidelines for every sector guiding every Government authority and NPO for disaster risk reduction activities without any confusions, which has helped all stakeholders, including private sectors, to take DRM initiatives in their own [7].

\section{Take-Home from Japan for Improved Disaster Risk Management in Nepal}

Having conducted several interactions, observation visits and reviewing literature on DRM practices in Japan, the authors are highly encouraged to think about how Nepal can get benefit from the Japanese experience and improve upon the current status of disaster risk management in Nepal. In particular, at a time when Nepal has recently transformed to federal set up of government from a centralized unitary system, there is a fresh opportunity to define the responsibilities of the national and local level governments and other stakeholders and improving DRM policy and guidelines for developing disaster resilient country.

Nepal, like Japan, a country of multi-hazard risks in the world largely owing to its diverse physiography, active seismicity, inadequate interventions for disaster risk reduction and alert of socio-economic vulnerabilities. A landlocked country, Nepal does not experience oceanic disasters and volcanos. However, apart from earthquake, fires (both-domestic and forest), floods, landslides, Glacial Lake Outburst Floods (GLOF), droughts, avalanches are quite common causing significant loss of lives and property every year. Earthquakes, mainly, have devastated the country many times affecting its economy and development negatively, and disrupting daily life of the citizens. In this context, as the DRM mechanism adopted in Japan has been considered as one of the successful examples in the world, the learnings from Japan might be helpful for overcoming with the challenges and improving DRM mechanism as a whole in Nepal.

The mechanism adopted in every aspects of DRM in Japan may exactly not be replicable in the context of Nepal, mainly due to reasons, such as weaker economy, geographical hardship and lack of connectivity by roads and infrastruc- 
tures, differences in political system and technological awareness to name very few. However, the following learnings from Japan can be instrumental to move forward and build a resilient Nepal.

\section{Reliable Early Warning System}

Developing reliable early warning systems can alert people, as required, timely for taking safety measures against potential risk of hazard events. Just for an example, during three-month stay in Tokyo, the principal author experienced tremor three times, and was little bit panic every time. However, persons sitting next to him were all okay; they did not even care what happened. Later he came to know that the Japanese colleagues were confident because, if there occurs a big shaking, they know what they should do and in case of a big and far earthquake they were supposed to receive the warnings for evacuation and following safety measures. They said, what they experienced was just normal.

\section{Build Back Better}

Each disaster should be considered as an opportunity for building back better, but not just reconstruction as what it was before. This has been achieved after major disasters in Japan such as after 1995 Kobe (Great Hanshin-Awaji) Earthquake and 2011 Great East Japan Earthquake and Tsunami, etc. This approach has to be adopted in the context of ongoing reconstruction activities of post 2015 earthquake in Nepal.

\section{Proactive Approach}

Priority should be given for investing in pre-disaster activities (mitigation and preparedness), then for response-related activities. Giving priority to pre-disaster activities will ultimately reduce the risk significantly, decreasing the required investment for response during and after disasters.

\section{Periodic Review and Update of DRM Policy and Plans}

After each disaster, critically analyze the countermeasures taken by all sectors and practicality of provisions made by the existing policy and plans, and programs based on the identified needs, revise and develop the policy and plans.

\section{Sector Specific Plans and Standard Operating Procedures}

DRM is collective effort. Every sector has roles and responsibilities for disaster risk management. Hence, under the guidance of national act, sector specific plans, policies, guidelines and standard Operating Procedures (SOPs) should be developed for effective DRM. Respective sectors should be given the responsibility for reviewing and updating such policies, plans and guidelines.

\section{Culture of Safety}

Promote peoples' understanding on the potential disasters and help them to imagine about the consequences and their actions to cope with, in case of real disasters. An effective awareness activity should achieve positive change in perception and beliefs of every individuals, when every citizen understands the value of safety and integrates/considers in daily activities as culture of safety, that ultimately reduces disaster risk.

Promote the mechanism of self-effort and mutual-help for effective disaster risk management. 
Motivate and encourage citizens for getting involved in DRM activities in different ways (designating special days for different themes could be one of the good examples).

Cash the experiences and real stories from disasters motivating people for getting prepared against disasters.

\section{Conclusion}

Nepal and Japan, both are multi-hazard prone countries; both have experienced several devastating disasters. The natural hazard events will occur naturally; nobody can stop at source, but the level of impact can be significantly varied depending on the level of preparedness, mitigation measures and response capacity, and as a whole effectiveness of DRM mechanism. Due to several factors, the level of risk is many times higher to the people living in Nepal than people living in Japan. For instance, a study carried out by GeoHazard International, United Nations Centre for Regional Development (UNCRD) shows that a person living in Kathmandu is about 60 times more likely to be killed by earthquake than a person living in Tokyo [6]. It was in 1982 the first act, Natural Calamity Relief Act, enacted addressing disaster-related issues in Nepal. Since then there have been several efforts for policy development and institutional arrangement for reducing risk management. However, despite these efforts in formulating disaster management policy and plans, as compared to many other countries, Nepal remains far behind in reviewing and updating them, which has pushed the country's risk management approach backward and the primarily reactive [21]. In this context, Nepal can learn from Japan as it has been considered as leader for readiness [18] and one of the successful examples for disaster risk management in the world. The specific disaster risk reduction measures can be different as per the local context; however, in general the principles are same and can be adopted anywhere. Japan has set up proficient level in DRM system, which includes, hazard specific countermeasures, public awareness, contextual revision of policy and plans and above all its perseverance in ruling innovations in coping with disasters. Although Nepal differs in socio-economic cultural and geopolitical aspects from Japan, but these good practices of DRM in Japan can be certainly be taken as a guide to develop effective DRM system in Nepal.

\section{Acknowledgements}

This paper is a part of Ph.D. research being conducted under JSPS RONPAKU Program from Institute of Industrial Science (IIS), the University of Tokyo.

We hereby acknowledge with gratitude to the persons who have provided extensive information, ideas and support, namely, Ms. Setsuko Saya, Director, International Cooperation Division, DM bureau, Cabinet Office, Government of Japan; Mr. Kendra Hirata, Director of Programs, CITYNET Yokohama Project Office, International Organizations Center; Mr. MasakuMotose, Bousai Network Labo; Ms. Yuka Matsumoto, Department of International Studies, the University 
of Tokyo and professionals from Yokohama Fire Bureau and Crisis Management Office.

\section{Conflicts of Interest}

The authors declare no conflicts of interest regarding the publication of this paper.

\section{References}

[1] Meguro, K. (2015) Lessons Learned from Past Big Earthquake Disasters and Comprehensive Disaster Management for Implementation of Disaster Resilient Society.

[2] UNISDR (2015) Proceedings, Third UN World Conference on Disaster Risk Reduction, Sendai, Japan, 14-18 March 2015.

https://www.preventionweb.net/files/45069_proceedingsthirdunitednationsworldc.pdf

[3] IFRC (2016) World Disaster Report 2016. Resilience: Saving Lives Today, Investing for Tomorrow, International Federation of Red Cross and Red Crescent Societies. http://www.ifrc.org/Global/Documents/Secretariat/201610/WDR\%202016-FINAL_ web.pdf

[4] Cabinet Office (2015) White Paper, Disaster Management in Japan 2015. Government of Japan.

http://www.bousai.go.jp/kaigirep/hakusho/pdf/WP2015_DM_Full_Version.pdf

[5] Numada, M. and Meguro, K. (2015) Process-Based Disaster Management System BOSS. New Technologies for Urban Safety of Mega Cities in Asia (USMCA) October 2015, Kathmandu.

[6] TMG (2015) Disaster Preparedness Tokyo: Let's Get Prepared, Tokyo Metropolitan Government.

http://www.bousai.metro.tokyo.jp/book/pdf/en/02_Lets_Get_Prepared.pdf

[7] Cabinet Office (2017) White Paper, Disaster Management in Japan. Government of Japan. http://www.bousai.go.jp/kyoiku/panf/pdf/WP2017_DM_Full_Version.pdf

[8] Jimee, G.K., Dixit, A.M., Tandingan, M.T. and Sharma, S. (2015) Strategy for Developing Professional Emergency Responders in Nepal. The 14th International Symposium on New Technologies for Urban Safety of Mega Cities in Asia, Kathmandu, 29-31 October 2015.

[9] MOHA (2011) Nepal Disaster Report: Policies, Practices and Lessons. Ministry of Home Affairs, Kathmandu.

[10] MOHA (2016) Nepal Disaster Report: Policies, Practices and Lessons. Ministry of Home Affairs, Kathmandu.

[11] Jimee, G.K., Van Westen, C.J. and Botero, V. (2008) Seismic Vulnerability and Capacity Assessment at Ward Level: A Case Study of Ward No. 20, Lalitpur Sub-Metropolitan City, Nepal. The 14th World Conference on Earthquake Engineering, Beijing, 12-17 October 2008.

[12] MOHA (2018) Disaster Risk Reduction and Management in Nepal. Asian Ministerial Conference on Disaster Risk Reduction, Ulaanbaatar, 3-6 July 2018.

[13] Ito, T. (2015) Considerations Concerning "How Should the Central and Local Government Respond in Emergency Situations Such as Natural Disasters". New Technologies for Urban Safety of Mega Cities in Asia (USMCA) October 2015, Kathmandu.

[14] Ogata, T. (2016) Disaster Management in Japan. Japan Medical Association Journal, 
59, 27-30.

[15] Go, J. (2005) National Report of Japan on Disaster Reduction. World Conference on Disaster Reduction, Kobe-Hyogo, 18-22 January 2005.

https://www.unisdr.org/2005/mdgs-drr/national-reports/Mozambique-report.pdf

[16] Saya, S. (2017) Disaster Management Policies of Japan. International Cooperation, Disaster Management Bureau, Cabinet Office, Government of Japan, Tokyo.

[17] Benarji, P. and Singh, N. (23013) Comparative Analysis of Disaster Management between Japan \& India. IOSR-JBM, 13, 62-74.

https://doi.org/10.9790/487X-1366274

[18] Rauhala, E. (2011) How Japan Became a Leader in Disaster Preparation? http://content.time.com/time/world/article/0,8599,2058390,00.html

[19] TMG (2014) Tokyo Disaster Prevention Plan: Becoming the World's Safest, Most Secure City, Tokyo Metropolitan Government, 2014

[20] Pedroso, F.F., Teo, J., Seville, E., Givanazzi, S. and Vargo, J. (2013) Post Disaster Challenges and Opportunities: Lessons from the 2011 Christchurch Earthquake and Great Eastern Japan Earthquake and Tsunami. Input Paper Prepared for the 2015 Global Assessment Report on Disaster Risk Reduction.

[21] MOHA (2017) Nepal Disaster Report 2017: The Road to Sendai. Ministry of Home Affairs, Kathmandu. 